\title{
Desempenho de pontas de pulverização na deposição de gotas de pulverização na cultura do amendoim
}

\section{Spray nozzles performance in the deposition of spray droplets on peanut crop}

\author{
Andreia Cristina Peres Rodrigues da Costa ${ }^{1 *}$; Dagoberto Martins ${ }^{2}$; Neumárcio \\ Vilanova da Costa ${ }^{3}$; Maria Renata Rocha Pereira ${ }^{4}$; José Iran Cardoso da Silva ${ }^{5}$
}

\begin{abstract}
Resumo
O objetivo deste estudo foi o de avaliar o efeito de pontas de pulverização na deposição de gotas na cultura do amendoim da cultivar 'Runner IAC 886'. O estudo foi realizado a campo, sendo as aplicações dos tratamentos realizadas nos estádios vegetativo (V1) e reprodutivo (R2). Foi utilizado como marcador o corante Azul Brilhante FDC -1 na concentração de 500 ppm. Os tratamentos foram constituídos por sete pontas de pulverização: XR 110015 VS $\left(150 \mathrm{~L} \mathrm{ha}^{-1}\right)$, XR $11002 \mathrm{VS}\left(200 \mathrm{~L} \mathrm{ha}^{-1}\right)$, TX-VK 6 (150L ha $\left.^{-1}\right)$, TX-VK 8 (200 L ha $\left.{ }^{-1}\right)$, AI 110015 VS (150 L ha-1), AI11002 VS (200 L ha-1) e TJ60 11002 VS (150 e $200 \mathrm{~L} \mathrm{ha}^{-1}$ ). Utilizou-se o delineamento em blocos ao acaso, com 4 repetições. Após a aplicação, as plantas foram imediatamente coletadas, e lavadas em $100 \mathrm{~mL}$ de água destilada para posterior quantificação do marcador em espectrofotômetro. Para as análises qualitativas, cada planta selecionada ao acaso dentro da faixa de aplicação da barra foi considerada uma repetição, o que representou um total de 100 repetições. Os dados obtidos foram ajustados à curva de regressão pelo modelo de Gompertz. Os resultados evidenciaram que independente do volume de aplicação as pontas AI 110015 VS e AI 11002 VS, foram as que proporcionaram maiores depósitos de calda de pulverização em plantas de amendoim em estádio vegetativo (V1) e reprodutivo (R2), respectivamente. Em volume baixo de aplicação as pontas AI 110015 VS e TJ60 11002 VS, foram as que proporcionaram as maiores uniformidade de distribuição da calda em plantas de amendoim Cultivar 'Runner IAC 886' em estádio vegetativo (V1) e reprodutivo (R2) respectivamente, e os maiores depósitos e maiores porcentagem de falhas nas aplicações, foram encontrados em plantas mais jovens comparando os estádios fenológicos de aplicação, independente da ponta e volume.
\end{abstract}

Palavras-chave: Ponta de pulverização, tecnologia de aplicação, uniformidade de deposição

\begin{abstract}
The objective of this study was to evaluate the effect of nozzles on spray droplet deposition in the peanut crop cultivar 'Runner IAC 886'. The study was conducted in the field, and the applications of treatments performed in the vegetative stage (V1) and reproductive (R2). It was used the Brilliant Blue FDC - 1 as tracer in water solution, at $500 \mathrm{ppm}$. The treatments consisted of seven spray nozzle XR $110015 \mathrm{VS}$ (150 L ha-1), XR 11002 VS (200 L ha-1), TX-VK 6 (150L ha-1), TX-VK 8 (200 L ha' $)$, AI 110015 VS
\end{abstract}

\footnotetext{
1 Pós-doutoranda, Universidade Estadual do Oeste do Paraná, UNIOESTE, Marechal Candido Rondon. E-mail: andreiacpr@, hotmail.com

2 Prof. Dr. do Dept ${ }^{\mathrm{o}}$ de Agricultura e Produção Vegetal, Faculdade de Ciências Agronômicas, UNESP, Botucatu. E-mail: dmartins@ fca.unesp.br

3 Prof. Dr. do Centro de Ciências Agrárias, UNIOESTE, Marechal Candido Rondon. E-mail: neumarciovc@hotmail.com

4 Pós-doutoranda, Faculdade de Ciências Agronômicas, UNESP, Botucatu, SP. E-mail: mariarenata10@hotmail.com

5 Pós-doutorando, Universidade Federal do Tocantins, UFT, Gurupi, TO. E-mail: joseiranc@hotmail.com

* Autor para correspondência
}

Recebido para publicação 27/06/2010 Aprovado em 31/07/2011 
(150 L ha $\left.{ }^{-1}\right)$, AI11002 VS (200 L ha-1) e TJ60 11002 VS (150 e $\left.200 \mathrm{~L} \mathrm{ha}^{-1}\right)$. It was used a randomized blocks design, with four replications. After application, plants were immediately collected, and washed in $100 \mathrm{~mL}$ of distilled water for posterior tracer quantification in spectrophotometer. The data had been adjusted a regression curve for Gompertz model. The results had evidenced that at low volumes of application the nozzle AI 110015 VS and TJ60 11002 VS, were the ones with best distribution uniformity of spray on plants of peanut cultivar 'Runner IAC 886' in the vegetative stage (V1) and reproductive (R2) respectively, and the largest deposits and higher percentage of failures in applications have been found in younger plants by comparing the growth stages of application, regardless of the spray nozzle and volume.

Key words: Spray nozzle, application technology, uniformity of deposition

\section{Introdução}

A cultura do amendoim (Aracahis hypogaea L.) é cultivada em todo o território brasileiro, geralmente em áreas de renovação de canaviais e de pastagens, onde nas regiões Centro-Oeste, Sul e Sudeste podem-se obter duas safras por ano (águas e seca), com médias de produtividades de grãos superiores a $2.000 \mathrm{~kg}$ ha1. De acordo com as estimativas da Conab (2009), a produção brasileira do amendoim no ano agrícola 2008/09 foi em torno de 301,3 mil toneladas, em 113,8 mil hectares cultivados. A região Sudeste do Estado de São Paulo destacou-se dentre as demais regiões produtoras, contribuindo com $77,7 \%$ da produção nacional.

Além de possuir elevado valor nutricional, os grãos do amendoim podem conter de 40 a $50 \%$ de teor de óleo, ressaltando sua importância como fonte alimentar e/ou como matéria prima para produção de biocombustíveis. Contudo, a produtividade média em várias regiões do País é considerada baixa, em razão de fatores edafoclimáticos, fitotécnicos, incidência de pragas e doenças, bem como a interferência de plantas daninhas.

As principais pragas e doenças que ocorrem na cultura podem causar redução de 20 a $62,7 \%$ na produção de vagens, quando medidas de controle não são utilizadas (MONFORT et al., 2004; CANTONWINE et al., 2006; MORAES et al., 2006).

Da mesma forma, a interferência das plantas daninhas na cultura do amendoim pode reduzir de 10,5 a 92\% a produtividade de grãos (AGOSTINHO et al., 2006; DIAS et al., 2009). Desta maneira, a utilização de herbicidas para o controle das plantas daninhas destaca-se como a alternativa mais eficiente, considerando principalmente extensas áreas de cultivo, porém, ainda há pouca informação na literatura sobre as técnicas mais adequadas de aplicação utilizada para estes produtos químicos na cultura do amendoim.

Os estudos sobre a eficiência das pulverizações em diferentes culturas demonstraram que podem ocorrer perdas por deriva entre 49 a $88 \%$ do total do produto aplicado (PERGHER; GUBIANI; TONETTO, 1997; CHAIM; VALARINI; PIO, 2000; SOUZA; VELINI; PALLADINI, 2007). Desta forma, considerando o manejo de plantas daninhas, a ocorrência de perdas de produto durante as operações de pulverização pode resultar em falhas de controle, seleção de biótipos resistentes a herbicidas, além de causar contaminações ambientais diretas e indiretas.

De acordo com Souza, Velini e Palladini (2007), a presença das plantas daninhas próxima da linha da cultura pode promover irregularidades nos depósitos das gotas de pulverização e exigir aumentos na dose de herbicidas para que elevados níveis de eficiência de controle sejam alcançados em condições de campo. Incrementos no volume da calda aplicada propiciam aumento na quantidade de calda retida, até certo ponto, a partir do qual a superfície tratada não mais retém o líquido. O excesso da calda que a folha não comporta escorre, concorrendo para a contaminação do solo. A adequação do volume da calda a ser aplicada que satisfaça a necessidade de molhamento foliar até o ponto de escorrimento, com o mínimo de desperdício, requer estudos para viabilizar e otimizar a aplicação (CUNHA et al., 2005). Outro fator importante para se adequar o 
volume aplicado é o estádio de desenvolvimento da planta.

Independentemente da finalidade das operações de pulverização, seja para o controle de agentes patogênicos, insetos ou de plantas daninhas, a maior deposição no alvo depende de fatores, como: volume de aplicação; tipo de bico ou ponta de pulverização; ângulo do bico; além das características inerentes a cada tipo de alvo como, por exemplo: estruturas morfoanatômicas foliares; arquitetura do dossel da planta; estádios fenológicos suscetíveis e local preferencial de incidência da doença ou do inseto na planta (KNOCHE, 1994; BERNI et al., 1999).

Entretanto, a eficiência do tratamento fitossanitário com a utilização de produtos de ação sistêmica ou de contato, não depende somente da quantidade de produto ativo depositado no alvo, mas também da uniformidade de distribuição deste produto sobre a superfície do alvo, sendo atribuição do processo de aplicação distribuir homogeneamente o produto no alvo por meio da técnica mais adequada para determinado manejo de controle.

Têm-se observado em campo inúmeras falhas nas operações de pulverização agrícolas, as quais podem estar relacionadas a erros na aplicação dos produtos. A calda pulverizada pode não estar atingindo as plantas de forma adequada, com uma boa deposição das gotas sobre suas folhas. Ressalta-se quenão foram encontradas informações na literatura que avaliem a qualidade e quantidade da deposição de calda de pulverização em plantas de amendoim, justificando-se a realização deste estudo. Assim, o presente trabalho teve como objetivo avaliar o efeito de pontas de pulverização na deposição de gotas na cultura do amendoim da cultivar 'Runner IAC 886'.

\section{Material e Métodos}

O presente trabalho foi instalado e conduzido a campo,naFazendaExperimental Lageado daFaculdade de Ciências Agronômicas - FCA/UNESP, campus de Botucatu/SP no ano de 2006. Utilizou-se para o estudo a cultivar 'Runner IAC 886' de amendoim.

A semeadura do amendoim foi realizada no dia 01/02/2006, no espaçamento de $0,9 \mathrm{~m}$ entrelinhas e 25 sementes por metro para obter-se a densidade de 10 a 12 plantas por metro. Antes da semeadura foi realizado o tratamento de sementes, com Tiametoxam (70g i.a. $100 \mathrm{~kg}^{-1}$ de semente). Durante o período experimental a cultura permaneceu livre da interferência de plantas daninhas por meio de capinas manuais.

O estudo foi conduzido no delineamento em blocos ao acaso, com 4 repetições. Na Tabela 1, estão descritos os tratamentos utilizados no experimento, em cada época de aplicação.

Tabela 1. Descrição dos tratamentos utilizados no experimento, em cada época de aplicação. Botucatu/ SP, 2006.

\begin{tabular}{|c|c|c|c|c|c|c|}
\hline Ponta* & Descrição & $\begin{array}{c}\text { Classificação } \\
\text { do tamanho } \\
\text { de gotas* }\end{array}$ & $\begin{array}{l}\text { Volume de } \\
\text { aplicação } \\
\mathrm{L} \mathrm{ha}^{-1}\end{array}$ & $\begin{array}{c}\text { Vazão } \\
\text { da ponta } \\
\text { L min } \text { mi }^{-1}\end{array}$ & KPa & $\begin{array}{c}\text { Velocidade } \\
\mathbf{k m ~ h}^{-1} \\
\end{array}$ \\
\hline XR Teejet & XR 110015VS & Fina & 150 & 0,45 & 175 & 3,6 \\
\hline XR Teejet & XR 11002VS & Média & 200 & 0,60 & 175 & 3,6 \\
\hline Conejet & TX-VK6 & Muito fina & 150 & 0,50 & 500 & 4,0 \\
\hline Conejet & TX-VK8 & Muito fina & 200 & 0,67 & 500 & 4,0 \\
\hline AI Teejet & AI $110015 \mathrm{VS}$ & Muito grossa & 150 & 0,45 & 200 & 3,6 \\
\hline AI Teejet & AI 11002VS & Muito grossa & 200 & 0,60 & 200 & 3,6 \\
\hline Twinjet & TJ60 11002VS & Fina & 150 & 0,60 & 175 & 4,8 \\
\hline Twinjet & TJ60 11002VS & Fina & 200 & 0,60 & 175 & 3,6 \\
\hline
\end{tabular}

* Fonte: Spraying Systems Co. (2003). Classes de gotas com base no diâmetro mediano volumétrico - DMV: Muito fina $(\mathrm{DMV}=<100 \mu \mathrm{m})$; Fina $(\mathrm{DMV}=100-175 \mu \mathrm{m})$; Média $(\mathrm{DMV}=175-250 \mu \mathrm{m})$ e Muito grossa $(\mathrm{DMV}=375-450 \mu \mathrm{m})$. 
A aplicação da calda de pulverização foi realizada aos 18 dias após a semeadura (DAS) da cultura do amendoim, correspondendo a $1^{\mathrm{a}}$ época e aos $42 \mathrm{DAS}$, correspondendo a $2^{\mathrm{a}}$ época. $\mathrm{Na}$ ocasião da aplicação dos tratamentos, na $1^{\mathrm{a}}$ e $2^{\mathrm{a}}$ épocas, as plantas de amendoim encontravam-se nos estádios vegetativo (V1) e reprodutivo (R2), respectivamente, conforme descrição de Boote (1982).

Os tratamentos foram aplicados com o auxílio de um pulverizador costal, pressurizado a $\mathrm{CO}_{2}$, equipado com uma barra com 4 pontas de pulverização espaçadas a $0,5 \mathrm{~m}$ entre si. No momento da aplicação a barra de pulverização estava distante $0,5 \mathrm{~m}$ das plantas de amendoim. Durante a aplicação dos tratamentos, as parcelas foram protegidas com auxílio de placas de lona plástica $(1,5 \times 2,5 \mathrm{~m})$ para evitar-se possível deriva para as parcelas vizinhas.

Para as avaliações de depósitos nas plantas, as pulverizações foram feitas com um traçador alimentício, o corante Azul Brilhante (FD\&C1). A preparação da calda foi realizada a partir da diluição em água destilada do corante Azul Brilhante na proporção de $500 \mathrm{mg} \mathrm{L}^{-1}$. As condições meteorológicas no período das aplicações variaram entre 28,9 a $33,9^{\circ} \mathrm{C}$ de temperatura e de 33 a $65 \%$ de umidade relativa do ar, sendo que e a velocidade média do vento foi de $2,5 \mathrm{~km} \mathrm{~h}^{-1}$.

Caixas plásticas tipo Gerbox com dimensões $11,5 \times 11,5 \times 3,0 \mathrm{~cm}$ foram utilizadas como alvo não biológico e colocadas em cada parcela experimental com o objetivo de avaliar-se a quantidade de calda depositada no solo. As caixas foram distribuídas antes das aplicações dos tratamentos nas 4 linhas centrais da parcela, sendo colocadas 4 Gerbox na linha e 4 na entre linhas da cultura.

Imediatamente após a aplicação da calda de pulverização foram coletadas ao acaso em cada parcela 25 plantas de amendoim. As plantas foram coletadas rentes ao solo com o auxílio de pinças e tesouras, sendo posteriormente acondicionada cada planta em sacos plásticos individuais devidamente etiquetados e em seguida levadas ao laboratório para serem lavadas com água destilada, para recuperação do traçante. As caixas Gerbox provenientes de cada parcela experimental receberam o mesmo procedimento.

No laboratório, frascos plásticos de cor âmbar com capacidade para $250 \mathrm{~mL}$ continham 100 e 150 $\mathrm{mL}$ de água destilada para lavagem das plantas, nos estádios de desenvolvimento vegetativo (V1) e reprodutivo (R2), respectivamente. A água foi colocada no saco plástico contendo a planta e, em seguida, o mesmo foi agitado durante 25 segundos, devolvendo-se em seguida a solução para os frascos. Para a determinação da massa seca, as plantas foram colocadas em sacos de papel e levadas a uma estufa de ventilação forçada de ar para secagem por um período de 72 horas, a temperatura de $65 \pm 2^{\circ} \mathrm{C}$, até atingir peso constante.

Os frascos plásticos com as amostras do marcador extraído das plantas coletadas foram devidamente armazenados em uma sala escura. Em seguida, foram procedidas leituras de absorbância de todas as amostras obtidas em espectrofotômetro de feixe duplo, modelo CGB Cintra 20, operando com $10 \mathrm{~mm}$ de caminho ótico no comprimento de onda de $630 \mathrm{~nm}$ para o corante Azul Brilhante (FD\&C-1), seguindo a metodologia descrita por Souza, Velini e Palladini (2007).

Osdados obtidos dos depósitos em porcentagem foram ajustados pelo modelo de Gompertz ( $\mathrm{F}=$ $\left.\mathrm{e}^{\wedge}\left(\mathrm{a}-\mathrm{e}^{\wedge}\left(-b-\mathrm{c}^{*} \mathrm{X}\right)\right)\right)$, para representar a freqüência acumulada (F) da deposição da calda pulverizada em percentagem. Adotou-se o valor 4,60517 para o parâmetro "a" do modelo, o qual representa a assíntota máxima da curva, em que "e $\mathrm{e}^{\mathrm{a}}=100$, conforme o modelo ajustado por Velini (1995). O deslocamento da curva ao longo do eixo x é 
representado pelo módulo do parâmetro "a", e a inclinação ou concavidade da curva em relação à freqüência acumulada, pelo parâmetro "c". Além disso, para melhor a visualização, optou-se por apresentar as freqüências não-acumuladas $(\mathrm{FN}=$ $\left.c^{*} \mathrm{e}^{\wedge}\left(\mathrm{a}-\mathrm{b}-\mathrm{c}^{*} \mathrm{X}-\mathrm{e}^{\wedge}\left(-\mathrm{b}-\mathrm{c}^{*} \mathrm{X}\right)\right)\right)$, que correspondem a derivada da primeira do modelo. As freqüências acumuladas e não-acumuladas do modelo de Gompertz permitem a interpretação biológica dos resultados. Para facilitar a visualização das informações, a derivada primeira corresponde à moda da deposição da solução pulverizada nos alvos específicos (VELINI, 1995).

Com o mesmo modelo foram calculados os valores de média, moda e os percentis 1,5 , e 10. Os percentis foram calculados igualando-se a expressão de freqüência acumulada a cada um destes valores, estimando a quantidade que recebe essa proporção de menor deposição da população de plantas avaliadas. A precisão do ajuste dos dados do modelo de Gompertz foi avaliada por meio dos coeficientes de determinação $\left(\mathrm{R}^{2}\right)$ e pela soma dos quadrados dos resíduos das equações.

Os resultados encontrados também foram submetidos à análise de variância pelo teste $\mathrm{F}$ e as médias comparadas pelo teste de LSD ao nível de $5 \%$ de probabilidade. A análise de variância e comparação de médias foi feita pelo programa SISVAR.

\section{Resultados e Discussão}

Na Tabela 2 encontram-se os resultados dos volumes médios de calda depositada no solo (caixa Gerbox) durante a aplicação nas plantas de amendoim, da cultivar 'Runner IAC 886' no estádio vegetativo (V1) da cultura. Os depósitos médios nos coletores situados na linha da cultura do amendoim no estádio vegetativo (V1) foram superiores aos encontrados na entrelinha da cultura. Isto pode ter ocorrido pelo fato das plantas de amendoim cultivar 'Runner IAC 886' serem de porte rasteiro, ou seja, possuem crescimento rente ao chão, o que cobriria a maior parte da superfície do solo, assim reter-se-iam os depósitos em suas folhas agindo como uma barreira para as gotas.

Não houve interação entre as pontas e a posição dos coletores. Os tratamentos que apresentaram maiores volumes de depósitos médios foram os correspondentes às pontas AI 11002 VS e AI 110015 VS, nos volumes de 200 e $150 \mathrm{~L} \mathrm{ha}^{-1}$, respectivamente. Detectou-se que o menor valor de depósitos encontrados foram verificados no tratamento com a ponta TX-VK 6 no volume de aplicação de $150 \mathrm{~L} \mathrm{ha}^{-1}$.

Nota-se na Tabela 3 que os resultados do efeito das pontas de pulverização não mostraram diferenças significativas na deposição, da calda pulverizada, nos coletores posicionados na linha e entrelinha da cultura do amendoim no estádio reprodutivo (R2). Contudo, analisando os depósitos posicionados na linha e na entrelinha da cultura, observou-se que o Gerbox posicionado na linha da cultura recebeu 70,0\% menos gotas do que o da entrelinha, indicando que, quanto mais próximas do amendoim estiverem as plantas daninhas, maior a dificuldade para se atingir o alvo. Esses resultados corroboram aqueles encontrados por Gazziero et al. (2006).

Verificou-se que as pontas AI 11002 VS seguida pela ponta XR 11002 VS, ambas em volume de aplicação de $200 \mathrm{~L} \mathrm{ha}^{-1}$, proporcionaram os maiores depósitos nos Gerboxes, sendo a ponta TX-VK 6 no volume de aplicação de $150 \mathrm{~L} \mathrm{ha}^{-1}$ a que proporcionou o menor depósito médio encontrado, repetindo os resultados observados nas aplicações realizadas no estádio vegetativo (V1), possivelmente devido à produção de gotas muito finas (DMV $<100 \mu \mathrm{m}$ ), que apresentam-se suscetíveis à deriva. 
Tabela 2. Volume médio de calda de pulverização depositada no solo (caixa Gerbox) durante a aplicação em estádio vegetativo (V1) de desenvolvimento de plantas de amendoim, na linha e entrelinha da cultura. Botucatu/SP, 2006.

\begin{tabular}{|c|c|c|c|c|}
\hline Ponta & $\left(\mathrm{L} \mathrm{ha}^{-1}\right)$ & Linha & Entrelinha & \multirow[t]{2}{*}{ Média } \\
\hline & & \multicolumn{2}{|c|}{$\mathrm{L} \mathrm{ha}^{-1}$} & \\
\hline XR 110015 VS & 150 & 141,00 & 75,39 & $108,19 \mathrm{~cd}$ \\
\hline XR 11002 VS & 200 & 151,85 & 86,32 & 119,08 bc \\
\hline TX VK 6 & 150 & 112,60 & 54,78 & $83,69 \mathrm{~d}$ \\
\hline TX VK 8 & 200 & 166,72 & 76,48 & $121,60 \mathrm{bc}$ \\
\hline AI 110015 VS & 150 & 167,38 & 130,39 & $148,88 \mathrm{a}$ \\
\hline AI 11002 VS & 200 & 188,22 & 87,69 & $137,95 \mathrm{ab}$ \\
\hline TJ60 11002 VS & 150 & 137,88 & 75,19 & $106,54 \mathrm{~cd}$ \\
\hline TJ60 11002 VS & 200 & 148,34 & 83,64 & $115,99 \mathrm{bc}$ \\
\hline Média & & $151,75 \mathrm{~A}$ & $83,73 \quad \mathrm{~B}$ & \\
\hline$\overline{\mathbf{F}_{\text {Ponta }}(P)}$ & & & $4,933 * *$ & \\
\hline $\mathbf{F}_{\text {Posicão }}(\mathbf{P o})$ & & & $115,148 * *$ & \\
\hline $\mathbf{F}_{(\mathbf{P}) \mathbf{x}(\mathbf{P o})}$ & & & $1,186^{\mathrm{ns}}$ & \\
\hline$F_{\text {Bloco }}$ & & & $0,335^{\mathrm{ns}}$ & \\
\hline D.M.S. (P) & & & 25,531 & \\
\hline D.M.S. (Po) & & & 12,766 & \\
\hline C.V. (\%) & & & 21,53 & \\
\hline
\end{tabular}

Médias seguidas de mesma letra maiúscula na linha e, minúscula na coluna, não diferem estatisticamente entre si pelo teste $\operatorname{LSD}(\mathrm{p} \leq 0,05)$.

** - valor significativo pelo teste " $\mathrm{F}$ " $(\mathrm{p} \leq 0,01)$.

ns - não significativo.

Ressalta-se que as pontas modelo AI e XR avaliadas proporcionaram gotas muito grossas $(\mathrm{DMV}=375$ a $450 \mu \mathrm{m})$ e médias $(\mathrm{DMV}=175$ a 250 $\mu \mathrm{m})$ o que diminui o risco de deriva, dependendo das condições ambientais. Contudo, Cunha et al. (2003) afirmam que, em geral, valores de DMV inferiores a $250 \mu \mathrm{m}$ indicam risco potencial de deriva, que acontece principalmente em virtude das gotas menores que $100 \mu \mathrm{m}$, em contrapartida, valores de DMV superiores a $500 \mu \mathrm{m}$ sugerem problemas de escorrimento, que, comumente, ocorrem com gotas maiores que $800 \mu \mathrm{m}$.

No geral, observou-se, que os maiores depósitos encontrados nos coletores presentes no solo foram proporcionados pelos tratamentos no volume de $200 \mathrm{~L} \mathrm{ha}^{-1}$, independente da ponta e/ ou posição dos coletores.

Comparando as deposições nos solos entre os dois estádios de desenvolvimento da cultura, verificou-se que os depósitos encontrados nos coletores, em aplicações no estádio vegetativo (V1) foram superiores aos depósitos encontrados nos coletores no estádio reprodutivo (R2) (Tabelas 2 e 3). Da mesma forma, Jensen e Spliid (2003) observaram que pulverizações em cereais nos estádios iniciais de desenvolvimento, a maior proporção da pulverização perdia-se para o solo comparado às aplicações em estádios mais avançados de desenvolvimento. 
Tabela 3. Volume médio de calda de pulverização depositada no solo (caixa Gerbox) durante a aplicação em estádio reprodutivo (R2) de desenvolvimento de plantas de amendoim, na linha e entrelinha da cultura. Botucatu/SP, 2006.

\begin{tabular}{|c|c|c|c|c|c|}
\hline Ponta & $\left(\mathbf{L ~ h a ^ { - 1 } )}\right.$ & Linha & Entrelinha & \multirow{2}{*}{\multicolumn{2}{|c|}{ Média }} \\
\hline & & \multicolumn{2}{|c|}{$\mathrm{L} \mathrm{ha}^{-1}$} & & \\
\hline XR 110015 VS & 150 & 15,65 & 71,76 & 43,71 & bcd \\
\hline XR 11002 VS & 200 & 28,07 & 90,31 & 59,19 & $\mathrm{ab}$ \\
\hline TX VK 6 & 150 & 10,41 & 52,43 & 31,42 & $\mathrm{~d}$ \\
\hline TX VK 8 & 200 & 27,02 & 75,69 & 51,36 & $\mathrm{bc}$ \\
\hline AI 110015 VS & 150 & 29,69 & 83,71 & 56,70 & $a b$ \\
\hline AI 11002 VS & 200 & 28,58 & 119,21 & 73,89 & $\mathrm{a}$ \\
\hline TJ60 11002 VS & 150 & 19,47 & 57,41 & 38,44 & $\mathrm{~cd}$ \\
\hline TJ60 11002 VS & 200 & 24,70 & 60,69 & 42,69 & bcd \\
\hline \multicolumn{2}{|l|}{ Média } & $22,95 \quad \mathrm{~B}$ & $76,40 \quad \mathrm{~A}$ & & \\
\hline \multicolumn{2}{|l|}{$\mathrm{F}_{\text {Ponta }}(\mathrm{P})$} & & $4,622 * *$ & & \\
\hline \multicolumn{2}{|l|}{$\mathrm{F}_{\text {Posição }}(\mathrm{Po})$} & & $145,242 * *$ & & \\
\hline \multicolumn{2}{|l|}{$\mathbf{F}_{(\mathbf{P}) \times(\mathbf{P o})}$} & & $1,966^{\mathrm{ns}}$ & & \\
\hline \multicolumn{2}{|l|}{$\mathbf{F}_{\text {Bloco }}$} & & $0,349^{\mathrm{ns}}$ & & \\
\hline \multicolumn{2}{|l|}{ D.M.S. (P) } & & 17,867 & & \\
\hline \multicolumn{2}{|l|}{ D.M.S. (Po) } & & 8,933 & & \\
\hline \multicolumn{2}{|l|}{ C.V. $(\%)$} & & 35,72 & & \\
\hline
\end{tabular}

Médias seguidas de mesma letra maiúscula na linha e, minúscula na coluna, não diferem estatisticamente entre si pelo teste $\operatorname{LSD}(\mathrm{p} \leq 0,05)$.

** - valor significativo pelo teste " $\mathrm{F}$ " $(\mathrm{p} \leq 0,01)$.

ns - não significativo.

Na Tabela 4, verificou-se que a interação entre pontas e estádio de desenvolvimento das plantas de amendoim não foi significativa a $5 \%$ de probabilidade pelo teste $\mathrm{F}$, indicando a independência entre os dois fatores. Na aplicação do marcador não houve diferença significativa entre as médias do volume de calda retido na folhagem com as diferentes pontas, independentemente da posição no dossel, apenas sendo significativo o estádio de desenvolvimento, no qual as plantas no estádio vegetativo (V1) apresentaram depósitos superiores aos encontrados nas plantas de amendoim no estádio reprodutivo (R2) na ordem de 296,7\%. Para as plantas selecionadas no estádio reprodutivo (R2) destaca-se a deposição da ponta AI 11002 VS em volume de $200 \mathrm{~L} \mathrm{ha}^{-1}$.

O fato da calda depositada por grama de massa seca média no estádio reprodutivo (R2) da cultura do amendoim ter sido inferior a quantidade depositada no estádio vegetativo (V1), deve-se ao maior dossel de folhas que apresentavam as plantas no momento da aplicação. Esses resultados corroboram os encontrados Gazziero et al. (2006) e Farinha et al. (2009) no qual o aumento do dossel de folhas também diminuiu proporcionalmente os depósitos sobre as plantas de soja. Segundo Ozeki e Kunz (1998), o momento oportuno para realizar a aplicação é um dos fatores considerados fundamentais para se obter êxito pleno na operação de controle. Dessa forma, a redução na deposição ao longo do tempo pode causar redução na eficiência, uma vez que, quanto maior a planta, menor será a disponibilidade de produto para fitointoxicação. Portanto, daí a necessidade de se aumentar o volume aplicado para manter a mesma cobertura de pulverização. 
Tabela 4. Volume médio de calda depositada em dois estádios de desenvolvimento de plantas de amendoim. Botucatu/SP, 2006.

\begin{tabular}{|c|c|c|c|c|}
\hline \multirow[t]{2}{*}{ Ponta } & \multirow[t]{2}{*}{$\left(\mathrm{L} \mathrm{ha}^{-1}\right)$} & $\begin{array}{c}\text { Estádio } \\
\text { Vegetativo (V1) }\end{array}$ & $\begin{array}{c}\text { Estádio } \\
\text { Reprodutivo (R2) }\end{array}$ & Média \\
\hline & & \multicolumn{3}{|c|}{$\mu \mathrm{L} \mathrm{g}^{-1}$ de massa seca } \\
\hline$\overline{\text { XR } 110015 \text { VS }}$ & 150 & 134,84 & 46,35 & 90,60 \\
\hline XR 11002 VS & 200 & 202,64 & 39,42 & 121,03 \\
\hline TX VK 6 & 150 & 183,78 & 30,35 & 107,07 \\
\hline TX VK 8 & 200 & 203,87 & 34,18 & 119,02 \\
\hline AI 110015 VS & 150 & 145,06 & 40,76 & 92,91 \\
\hline AI 11002 VS & 200 & 157,16 & 53,05 & 105,11 \\
\hline TJ60 11002 VS & 150 & 149,21 & 32,44 & 90,83 \\
\hline TJ60 11002 VS & 200 & 100,45 & 45,40 & 72,93 \\
\hline Média & & $159,63 \mathrm{~A}$ & 40,24 & \\
\hline$\overline{\mathbf{F}_{\text {Ponta }}(\mathbf{P})}$ & & & $0,680^{\mathrm{ns}}$ & \\
\hline $\mathrm{F}_{\text {Estádio }}(\mathrm{E})$ & & & $73,950 * *$ & \\
\hline $\mathbf{F}_{(\mathbf{P}) \times(\mathbf{E})}$ & & & $1,035^{\mathrm{ns}}$ & \\
\hline $\mathbf{F}_{\text {Bloco }}$ & & & $3,343 *$ & \\
\hline D.M.S. & & & 27,961 & \\
\hline C.V. (\%) & & & 55,57 & \\
\hline
\end{tabular}

Médias seguidas de mesma letra maiúscula na linha e, maiúscula na coluna, não diferem estatisticamente entre si pelo teste LSD $(\mathrm{p} \leq 0,05)$.

** - valor significativo pelo teste " $F$ " $(\mathrm{p} \leq 0,01)$.

* - valor significativo pelo teste " $F$ " $(\mathrm{p} \leq 0,05)$.

ns - não significativo.

$\mathrm{Na}$ Tabela 5, estão apresentados os valores correspondentes aos parâmetros calculados a partir do ajuste da regressão através do modelo de Gompertz para a frequência acumulada nos dois estádios de desenvolvimento.

O modelo de ponta TX-VK 8 seguida pela ponta TX-VK 6, nos volumes de 200 e $150 \mathrm{~L}$ $\mathrm{ha}^{-1}$, respectivamente, foram os tratamentos que apresentaram os maiores valores de moda (Tabela 6), indicando os maiores valores freqüentes de depósitos de calda que ocorreram nas plantas de amendoim no estádio vegetativo (V1). Os menores depósitos encontrados foram conferidos pela ponta TJ60 11002 VS nos dois volumes de aplicação. Quando se realizou aplicações nas plantas de amendoim no estádio reprodutivo (R2), observou-se que a ponta que proporcionou o maior depósito calda no estádio reprodutivo foi a ponta AI 11002 VS seguida pela ponta XR 110015 VS nos volumes de aplicação de 200 e $150 \mathrm{~L} \mathrm{ha}^{-1}$, respectivamente.

$\mathrm{Na}$ Tabela 6, observou-se, ainda, que o valor da moda, ou seja, os depósitos de calda reduziram progressivamente nas plantas de amendoim ao longo do desenvolvimento da cultura. Dessa forma, os dados obtidos permitem inferir que, quanto menor a planta de amendoim, maior será a retenção de calda pela parte área da cultura. Resultados semelhantes foram encontrados por Gazziero et al. (2006) em pulverizações em plantas de soja; Souza (2002) tanto em pulverização convencional como em eletrostática e por Tomazela et al. (2006) utilizando Brachiaria plantaginea. 


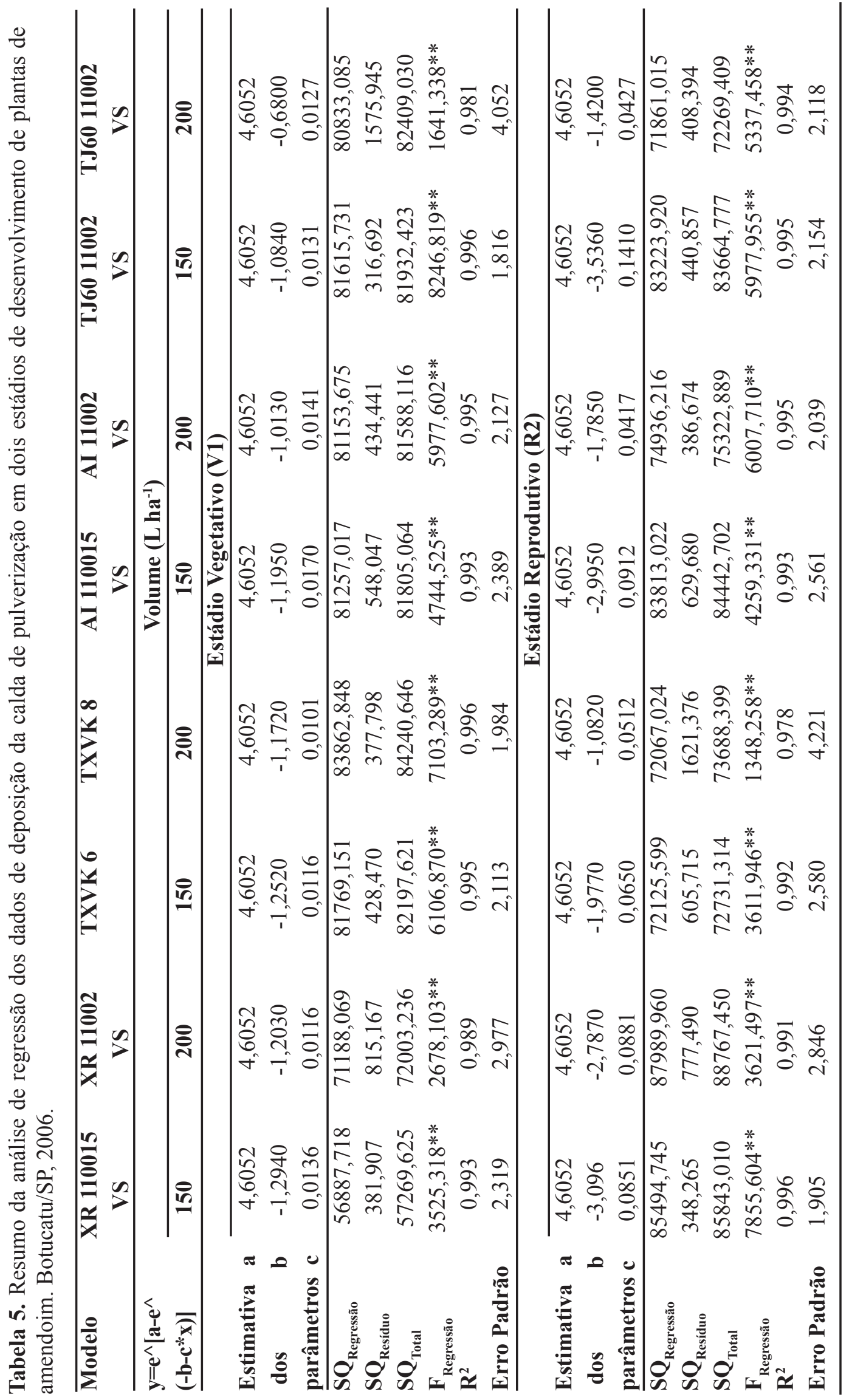


Tabela 6. Valores da moda dos depósitos da calda de pulverização em dois estádios de desenvolvimento de plantas de amendoim. Botucatu/SP, 2006.

\begin{tabular}{|c|c|c|c|}
\hline \multirow[t]{2}{*}{ Pontas } & \multirow[t]{2}{*}{$\left(\mathbf{L ~ h a} \mathbf{a}^{-1}\right)$} & $\begin{array}{c}\text { Estádio } \\
\text { Vegetativo (V1) }\end{array}$ & $\begin{array}{c}\text { Estádio } \\
\text { Reprodutivo (R2) }\end{array}$ \\
\hline & & \multicolumn{2}{|c|}{$\mu \mathrm{L} \mathrm{g}^{-1}$ de massa seca } \\
\hline XR 110015 VS & 150 & 95,15 & 36,38 \\
\hline XR 11002 VS & 200 & 103,71 & 31,63 \\
\hline TXVK 6 & 150 & 107,93 & 30,42 \\
\hline TXVK 8 & 200 & 116,04 & 21,13 \\
\hline AI 110015 VS & 150 & 70,29 & 32,84 \\
\hline AI 11002 VS & 200 & 71,84 & 42,81 \\
\hline TJ60 11002 VS & 150 & 82,75 & 25,08 \\
\hline TJ60 11002 VS & 200 & 53,54 & 33,26 \\
\hline
\end{tabular}

A qualidade da deposição pode ser analisada através das Figuras 1 e 2, nas quais estão apresentadas as deposições avaliadas pelo modelo de Gompertz.

A partir da frequência acumulada dada pelo modelo foi construída a Figura 1, no qual a menor inclinação da curva corresponde ao maior valor do parâmetro "c" do modelo (Tabela 5) e indicam a menor dispersão dos depósitos da calda $\mathrm{g}^{-1} \mathrm{de}$ massa seca de plantas no estádio vegetativo (V1). Isto, também pode ser visualizado por meio das frequências não acumuladas no qual, as curvas mais afuniladas correspondem à menor curtose dos dados e mostram a frequência de valores extremos, pois quanto mais plano for o pico maior será a curtose e pior será a homogeneidade dos depósitos.

$\mathrm{Na}$ avaliação das plantas de amendoim no estádio vegetativo (V1), os tratamentos que produziram os depósitos de calda mais uniformes foram os correspondentes as pontas que produzem gotas muito grossas (DMV $=375$ a $450 \mu \mathrm{m}) \mathrm{AI}$ 110015 VS e AI 11002 VS nos volumes de 150 e $200 \mathrm{~L} \mathrm{ha}^{-1}$, respectivamente. No entanto, as pontas TX-VK 8 (150 L ha-1), TX-VK 6 (200 L ha-1) que produzem gotas muito finas $(\mathrm{DMV}<100 \mu \mathrm{m})$ e XR 11002 VS (200 L ha-1) que produz gotas médias $(\mathrm{DMV}=175$ a $250 \mu \mathrm{m})$ proporcionaram as maiores variações de depósitos de de calda. A maior variação de deposição obtida pelas pontas TX-VK 8, TX-VK 6 e XR 11002 VS pode ser justificado, provavelmente devido a perdas das gotas muito finas e médias por deriva, em relação as pontas que produzem gotas muito grossas.

As menores variações foram obtidas quando se utilizou os menores volumes, independentes dos modelos de pontas avaliadas.

O volume aplicado numa pulverização deve ser o mais uniforme possível, sob pena de ser necessário volume adicional para compensar os pontos ou faixas que receberam menor quantidade de calda (PERECIN et al., 1998).

Na Figura 2 estão representadas as curvas de densidade de probabilidade (frequência não acumulada) da porcentagem do marcador nas plantas de amendoim no estádio reprodutivo (R2). Comparando-se as curvas do estádio reprodutivo (R2), com a curva dos depósitos no estádio vegetativo (V1) observou-se, que os depósitos apresentaram melhor uniformidade de distribuição das gotas de pulverização com as plantas mais velhas. 
Figura 1. Frequência acumulada - FA (\%) e não acumulada - FNA (\%), em função dos depósitos de calda de pulverização no estádio vegetativo (V1) de plantas de amendoim. Botucatu/SP, 2006.
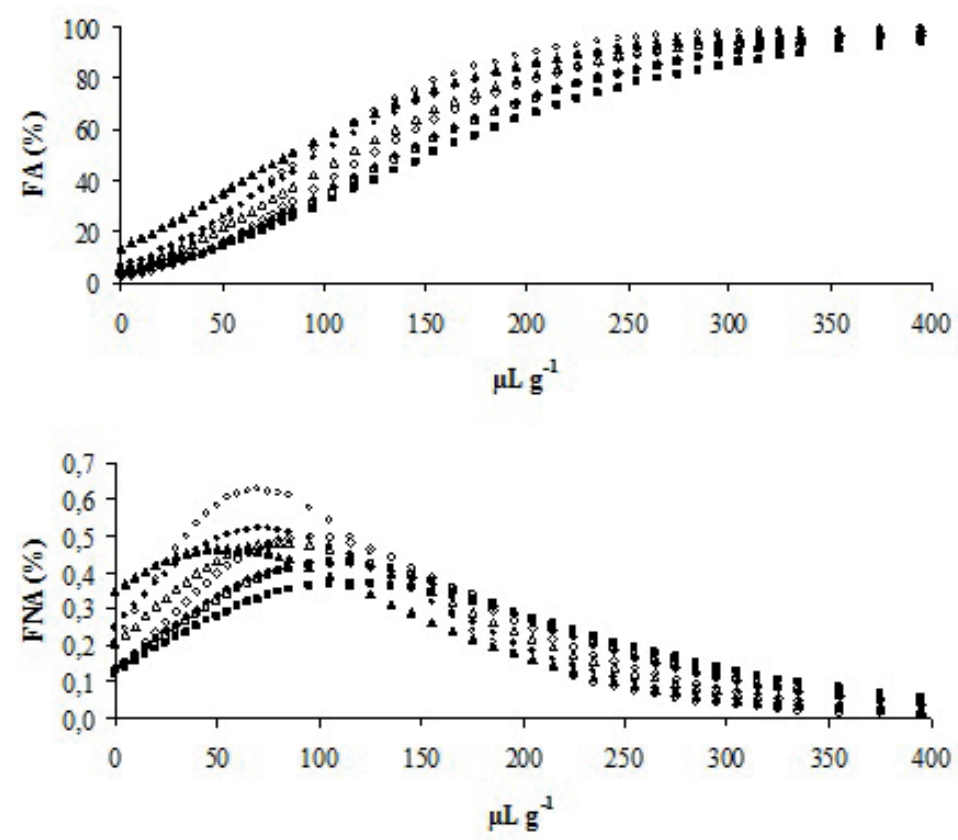

- XR(200 L/ha $) \circ X R(150 \mathrm{~L} / \mathrm{ha})+\mathrm{TJ}(200 \mathrm{~L} / \mathrm{ha})+\mathrm{TJ}(150 \mathrm{~L} / \mathrm{ha})$

- $\operatorname{TX}(200 \mathrm{~L} / \mathrm{ha}) \cdot \mathrm{TX}(150 \mathrm{~L} / \mathrm{ha}) \cdot \mathrm{AI}(200 \mathrm{~L} / \mathrm{ha})$ "AI (150L/ha)

Figura 2. Frequência acumulada - FA (\%) e não acumulada - FNA (\%), em função dos depósitos de calda de pulverização no estádio reprodutivo (R2) de plantas de amendoim. Botucatu/SP, 2006.
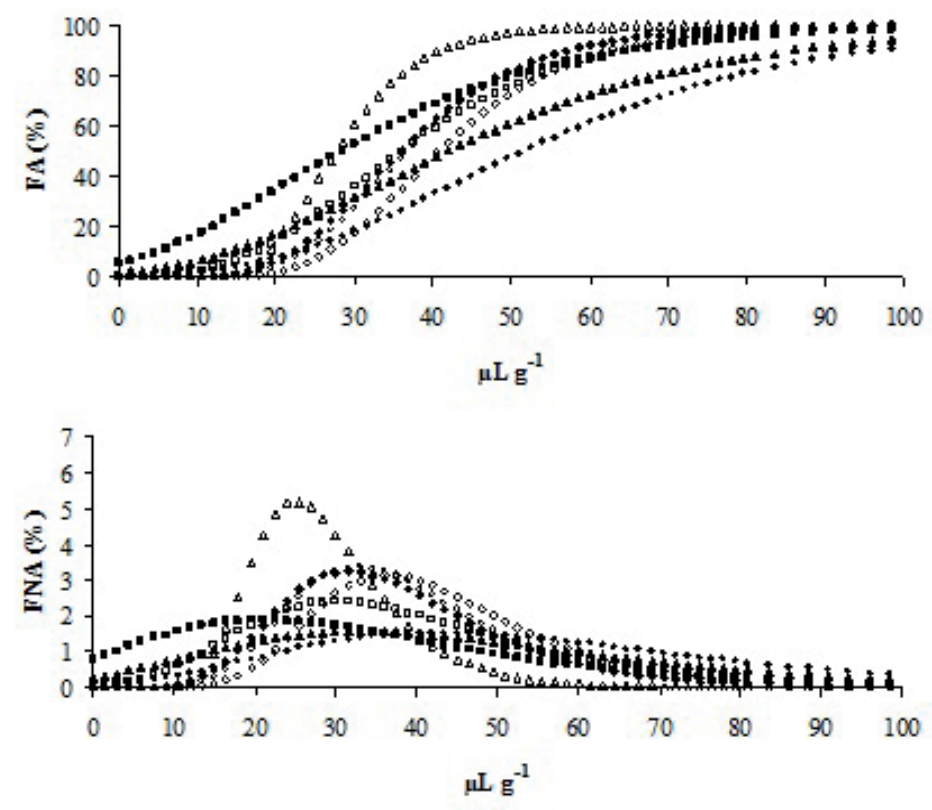

- XR (200 L/ha) *XR (150 L/ha) *TJ (200 L/ha) \& TJ (150 L ha)

- TX (200L/ha) a TX (150L/ha) $\cdot \operatorname{AI}(200 \mathrm{~L} / \mathrm{ha}) \quad$ AI (150L/ha) 
Notou-se que, a ponta TJ60 11002 VS seguida pela ponta AI $110015 \mathrm{VS}$, ambas no volume de $150 \mathrm{~L} \mathrm{ha}^{-1}$, proporcionaram as menores dispersões dos dados, o que conferiu uma melhor uniformidade de distribuição das gotas de pulverização, sendo também confirmado pelo parâmetro "c" que apresentou o maior valor (Tabela 5). Enquanto que, a ponta AI 110015 VS seguida pela ponta TJ60 11002 VS, ambas no volume de $200 \mathrm{~L}$ ha1 , proporcionaram as maiores dispersões dos dados e menor valor do parâmetro "c", sendo a concavidade da curva referente a essa ponta a mais plana, o que confere a essas pontas a maior desuniformidade entre todos os tratamentos estudados.

Destaca-se que a ponta AI 110015 VS (150 L ha-1) que produz gotas muito grossas proporcionou deposição uniformes da calda nas plantas de amendoim cultivar 'Runner IAC 886' nos estádios vegetativo (V1) e reprodutivo (R2), o que pode indicar boa alternativa de uso em pulverizações por contribuir com a menor perda de gotas por deriva, além de diminuir a perda de calda das folhas por escorrimento, como ocorre em altos volumes de aplicação.

Segundo Negrisoli et al. (2002), as irregularidades dos depósitos podem levara necessidade de aumento nas doses aplicadas, o que pode acarretar em incrementos das doses necessárias para um determinado controle para compensar as perdas. Apesar disto, o pesquisador ressalta que são escassos os estudos que procuram estabelecer a dispersão de depósitos no solo ou em populações de plantas.

Na Tabela 7 estão apresentados os valores dos depósitos da calda de pulverização em $\mu \mathrm{L}$ de calda $\mathrm{g}^{-1}$ de massa seca, nas populações de plantas de amendoim nos dois estádios de desenvolvimento, em que menos ocorreram depósitos.

Quando se avalia os depósitos nos dois estádios de desenvolvimento, observa-se que as plantas de amendoim no estádio vegetativo apresentaram os maiores depósitos médios e unitários, porém também as maiores falhas na aplicação da calda de pulverização. Verificou-se nas plantas de amendoim, no estádio vegetativo (V1), que todas as pontas testadas apresentaram falhas na pulverização, em pelo menos $1 \%$ das plantas amostradas, conferindo as pontas AI 11002 VS e TJ60 11002 nos volumes de 200 e 150 L $\mathrm{ha}^{-1}$ falhas em 5\% das plantas amostradas e falhas de 10\% das plantas pulverizadas com a ponta TJ60 11002 no volume de $200 \mathrm{~L} \mathrm{ha}^{-1}$.

Tabela 7. Deposição de calda de pulverização ( $\mu \mathrm{L} \mathrm{g}^{-1}$ de massa seca) em dois estádios de desenvolvimento, na população de plantas de amendoim, em que menos ocorreram depósitos. Botucatu/SP, 2006.

\begin{tabular}{|c|c|c|c|c|c|c|c|c|}
\hline Percentins & $\begin{array}{c}\text { XR } 110015 \\
\text { VS }\end{array}$ & $\begin{array}{l}\text { XR } 11002 \\
\text { VS }\end{array}$ & TXVK 6 & TXVK 8 & $\begin{array}{c}\text { AI } 110015 \\
\text { VS } \\
\end{array}$ & $\begin{array}{c}\text { AI 11002 } \\
\text { VS }\end{array}$ & $\begin{array}{c}\text { TJ60 } 11002 \\
\text { VS }\end{array}$ & $\begin{array}{c}\text { TJ60 } 11002 \\
\text { VS } \\
\end{array}$ \\
\hline \multirow[t]{3}{*}{$(\%)$} & \multicolumn{8}{|c|}{ Volume $\left(\mathrm{L} \mathrm{ha}^{-1}\right)$} \\
\hline & 150 & 200 & 150 & 200 & 150 & 200 & 150 & 200 \\
\hline & \multicolumn{8}{|c|}{ Estádio Vegetativo (V1) } \\
\hline $\mathbf{1}$ & 0,00 & 0,00 & 0,00 & 0,00 & 0,00 & 0,00 & 0,00 & 0,00 \\
\hline 5 & 14,47 & 9,12 & 13,35 & 7,41 & 5,75 & 0,00 & 0,00 & 0,00 \\
\hline 10 & 33,82 & 31,81 & 36,03 & 33,46 & 21,23 & 12,69 & 19,08 & 0,00 \\
\hline \multirow[t]{2}{*}{50} & 122,10 & 135,30 & 139,53 & 152,33 & 91,85 & 97,84 & 110,73 & 82,40 \\
\hline & \multicolumn{8}{|c|}{ Estádio Reprodutivo (R2) } \\
\hline 1 & 18,44 & 14,30 & 6,92 & 0,00 & 16,09 & 6,18 & 14,25 & 0,00 \\
\hline 5 & 23,49 & 19,18 & 13,54 & 0,00 & 20,81 & 16,49 & 17,30 & 7,56 \\
\hline 10 & 26,58 & 22,17 & 17,58 & 4,84 & 23,69 & 22,80 & 19,16 & 13,72 \\
\hline 50 & 40,69 & 35,79 & 36,05 & 28,29 & 36,86 & 51,60 & 27,68 & 41,84 \\
\hline
\end{tabular}


Para as plantas pulverizadas no estádio reprodutivo (R2), as falhas diminuíram significativamente, ocorrendo apenas com as pontas TJ 6011002 VS e TX-VK 8, ambas no volume de aplicação de $200 \mathrm{~L} \mathrm{ha}^{-1}$, proporcionando falhas de 1 e $5 \%$, respectivamente.

A ponta que proporcionou os maiores depósitos na população de plantas em que menos receberam pulverizações foi a ponta XR 110015 VS no volume de aplicação de $150 \mathrm{~L} \mathrm{ha}^{-1}$.

Para as condições em que o presente trabalho foi desenvolvido, pode-se concluir que as pontas AI 110015 VS e AI 11002 VS, foram as que proporcionaram maiores depósitos de calda de pulverização em plantas de amendoim em estádio vegetativo(V1) e reprodutivo(R2), respectivamente. Enquanto que, quando utilizou-se o volume de aplicação de $150 \mathrm{~L} \mathrm{ha}^{-1}$, as pontas AI $110015 \mathrm{VS}$ e TJ60 11002 VS, foram as que proporcionaram as maiores uniformidade de distribuição da calda em plantas de amendoim Cultivar 'Runner IAC 886' nos estádios vegetativo (V1) e reprodutivo (R2) respectivamente. Os maiores depósitos e maiores porcentagem de falhas nas aplicações, foram encontrados em plantas nos estádios vegetativo (V1) quando se comparam os estádios fenológicos de aplicação, independente da ponta e volume.

\section{Referências}

AGOSTINHO, F. H.; GRAVENA, R.; ALVES, P. L. C. A.; SALGADO, T. P.; MATTOS, E. D. The effect of cultivar on critical periods of weed control in peanuts. Peanut Science, Raleigh, v. 33, n. 1, p. 29-35, 2006.

BERNI, R. F.; MACHADO, V. O. F.; COSTA, G. R.; BARATA, G.; PAULA, R. S. Avaliação da cobertura de gotas provocada por diferentes bicos de pulverização na cultura do milho e do feijão. Pesquisa Agropecuária Tropical, Goiânia, v. 29, n. 1, p. 49-52, 1999.

BOOTE, K. J. Growth stages of peanut (Arachis hypogaea L.). Peanut Science, Raleigh, v. 9, n. 1, p. 3539, 1982.

CANTONWINE, E. G.; CULBREATH, A. K.; STEVENSON, K. L. R. C.; KEMERAIT JR., R. C.;
BRENNEMAN, T. B.; SMITH, N. B.; MULLINIX JUNIOR, B. G. Integrated disease management of leaf spot and spotted wilt of peanut. Plant Disease, St. Paul, v. 90, n. 4 , p. $493-500,2006$.

CHAIM, A.; VAlARINI, P. J.; PIO, L. C. Avaliação de perdas na pulverização de agrotóxicos na cultura do feijão. Pesticidas: Revista de Ecotoxicologia e Meio Ambiente, Curitiba, v. 10, n. 1, p. 65-74, 2000.

COMPANHIA NACIONAL DE ABASTECIMENTO CONAB. Acompanhamento de safra brasileira: grãos, décimo primeiro levantamento, agosto/2009. Companhia Nacional de Abastecimento. Brasília: Conab, 2009. Disponível em: <http://www.conab.gov.br/conabweb/ download/safra/11graos_08.09.pdf $>$. Disponível em: 07 set. 2009.

CUNHA, J. P. A. R.; TEIXEIRA, M. M.; COURY, J. R.; FERREIRA, L. R. Avaliação de estratégias para redução da deriva de agrotóxicos em pulverizações hidráulicas. Planta Daninha, Viçosa, v. 21, n. 2, p. 325-332, 2003.

CUNHA, J. P. A. R.; TEIXEIRA, M. M.; VIEIRA, R. F.; FENANDES, H. C. Deposição e deriva de calda fungicida aplicada em feijoeiro, em função de bico de pulverização e de volume de calda. Revista Brasileira de Engenharia Agrícola e Ambiental, Campina Grande, v. 9 , n. 1, p. 133-38, 2005.

DIAS, T. C. S.; ALVES, P. L. C. A.; PAVANI, M. C. M. D.; NEPOMUCENO, M. Efeito do espaçamento entre fileiras de amendoim rasteiro na interferência de plantas daninhas na cultura. Planta Daninha, Viçosa, v. 27, n. 2, p. 221-228, 2009.

FARINHA, J. V.; MARTINS, D.; COSTA, N. V.; DOMINGOS, V. D. Deposição da calda de pulverização em cultivares de soja no estádio R1. Ciência Rural, Santa Maria, v. 39, n. 6, p. 1738-1744, 2009.

GAZZIERO, D. L. P.; MACIEL, C. D. G.; SOUZA, R. T.; VELINI, E. D.; PRETE, C. E. C.; OLIVEIRA NETO, W. Deposição de glyphosate aplicado para controle de plantas daninhas em soja transgênica. Planta Daninha, Viçosa, v. 24, n. 1, p. 173-181, 2006.

JENSEN, P. K.; SPLIID, N. H. Deposition of spray liquid on the soil below cereal crops after applications during the growing season. Weed Research, Oxford, v. 43, n. 5, p. 362-370, 2003.

KNOCHE, M. Effect of droplet size and carrier volume on performance of foliage applied herbicides. Crop Protection, Oxford, v. 13, n. 3, p. 163-178, 1994.

MONFORT, W. S.; CULBREATH, A. K.; STEVENSON, K. L.; BRENNEMAN, T. B.; GORBET, D. W.; PHATAK, S. C. Effects of reduced tillage, resistant cultivars, and 
reduced fungicide inputs on progress of early leaf spot of peanut (Arachis hypogaea). Plant Disease, St. Paul, v. 88, n. 8, p. 858-864, 2004.

MORAES, A. R. A.; MORAES, S. A.; LOURENÇÃO, A. L.; GODOY, I. J.; MARTINS, A. L. M. Efeito da aplicação de thiamethoxam para controle do tripes na redução da severidade da verrugose do amendoim. Fitopatologia Brasileira, Lavras, v. 31, n. 2, p. 164-170. 2006.

NEGRISOLI, E.; TOFOLI, G. R.; VELINI, E. D.; MARTINS, D.; PALLADINI, L. A. Depósitos unitários de calda de pulverização com e sem surfactante em plantas de Salvinia molesta. Planta Daninha, Viçosa, v. 20, p. 51-6, 2002. Edição Especial.

OZEKI, Y.; KUNZ, R. P. Tecnologia de aplicação aérea aspectos práticos. In: Tecnologia e segurança na aplicação de agrotóxicos: novas tecnologias. Santa Maria: Departamento de Defesa Fitossanitária, Sociedade de Agronomia de Santa Maria, UFMS, 1998. p. 65-78.

PERECIN, D.; PERESSIN, V. A.; MATUO, T.; BRAZ, B. A.; PIO, L. C. Padrões de distribuição obtidos com bicos TF-4, TJ60-11006 e TQ15006 em mesa de prova. Pesquisa Agropecuária Brasileira, Brasília, v. 33, n. 2, p. 175-82, 1998.

PERGHER, G.; GUBIANI, R.; TONETTO, G. Foliar deposition and pesticide losses from three air-assisted sprayers in a hedgerow vineyard. Crop Protection, Oxford, v. 16, n. 1, p. 25-33, 1997.

SOUZA, R. T.; VELINI, E. D.; PALLADINI, L. A. Aspectos metodológicos para análise de depósitos de pulverizações pela determinação dos depósitos pontuais. Planta Daninha, Viçosa, v. 25, n. 1, p. 195-202, 2007.

SOUZA, R. T. Efeito da eletrização de gotas na variabilidade de depósitos de pulverização e eficácia teórica do glyphosate no controle de plantas daninhas na cultura da soja. 2002. Tese (Doutorado em Agronomia/ Agricultura) - Universidade Estadual Paulista, Botucatu.

SPRAYING SYSTEMS. Teejet spray products: guia do comprador 202-BR/P. Wheaton: Spraying Systems, 2003. $37 \mathrm{p}$.

TOMAZELA, M. S.; MARTINS, D.; MARCHI, S. R.; NEGRISOLI, E. Avaliação da deposição da calda de pulverização em função da densidade populacional de Brachiaria plantaginea, do volume e do ângulo de aplicação. Planta Daninha, Viçosa, v. 24, n. 1, p. 183189, 2006.

VELINI, E. D. Estudos e desenvolvimento de métodos experimentais e amostrais adaptados à matologia. 1995. Tese (Doutorado em Agronomia/Produção
Vegetal) - Faculdade de Ciências Agrárias e Veterinárias. Universidade Estadual Paulista, Jaboticabal. 